
\title{
BResarch Soute \\ Pharmacokinetics of Anti-Infective Agents During CytoSorb Hemoadsorption: An Experimental Study
}

\section{Antoine Schneider ( $\square$ antoine.schneider@chuv.ch )}

Centre Hospitalier Universitaire Vaudois https://orcid.org/0000-0003-0576-7094

\section{Pascal André}

Centre Hospitalier Universitaire Vaudois

Joerg Scheier

Cytosorbents Inc

\section{Monika Schmidt}

$\mathrm{HCx}$ consulting $\mathrm{GmBH}$

Heiko Ziervogel

CP Consulting

Thierry Buclin

Centre Hospitalier Universitaire Vaudois

\section{Detlef Kindgen-Milles}

University Hospital Dusseldorf: Universitatsklinikum Dusseldorf

\section{Research}

Keywords: Pharmacokinetics, anti-bacterial agents, antifungal agents, sepsis, drug monitoring, hemoadsorption, CytoSorb

Posted Date: December 30th, 2020

DOl: https://doi.org/10.21203/rs.3.rs-136014/v1

License: (c) (1) This work is licensed under a Creative Commons Attribution 4.0 International License.

Read Full License 


\title{
PHARMACOKINETICS OF ANTI-INFECTIVE AgENTS DURING CYTOSORB HEMOADSORPTION: AN EXPERIMENTAL STUDY
}

\author{
Authors: \\ Antoine G. Schneider, MD, $\mathrm{PhD}{ }^{1-2 *}$ \\ antoine.schneider@chuv.ch \\ Pascal André, PharmD, $\mathrm{PhD}^{3 *}$ \\ pascal.andre@chuv.ch \\ Joerg Scheier, MD ${ }^{4}$ \\ joerg.scheier@cytosorbents.com \\ Monika Schmidt ${ }^{5}$ \\ m.schmidt@medizin-im-gruenen.de \\ Heiko Ziervogel, $\mathrm{PhD}^{5}$ \\ h.ziervogel@medizin-im-gruenen.de \\ Thierry Buclin, $\mathrm{MD}^{3}$ \\ thierry.buclin@chuv.ch \\ Detlef Kindgen-Milles, MD ${ }^{4}$ \\ kindgen-milles@med.uni-duesseldorf.de \\ *: Both authors contributed equally to the work \\ 1. Adult Intensive Care Unit, Centre Hospitalier Universitaire Vaudois (CHUV), Lausanne, Switzerland \\ 2. Faculty of Biology and Medicine, University of Lausanne, Lausanne, Switzerland \\ 3. Clinical Pharmacology, Centre Hospitalier Universitaire Vaudois (CHUV), Lausanne, Switzerland \\ 4. CytoSorbents Europe GmbH, Berlin, Germany \\ 5. Medical Competence Center Berlin/Brandenburg c/o HCx Consulting GmbH, Wendisch Rietz, \\ Germany \\ 6. Dept. of Anesthesiology, University Hospital Düsseldorf, Germany
}

\section{Corresponding author:}

Dr Antoine G. Schneider

BH08-610, Centre Hospitalier Universitaire Vaudois (CHUV)

46, Avenue du Bugnon 1011, Lausanne Switzerland

Tel: +41213141632

Email: antoine.schneider@chuv.ch

Running Title: CytoSorb and pharmacokinetics of anti-infectives

Word Count: 2958 


\section{AbSTRaCT}

2 Background: Cytokine hemoadsorption might be effective in patients with sepsis. However, its

3 effect on anti-infective agents' pharmacokinetics remains largely unknown. We sought to

4 determine the influence of hemoadsorption on the pharmacokinetics of common anti-infective 5 agents.

6 Methods: This is an interventional experimental study, conducted in 24 healthy pigs. Animals 7 were randomly allocated to either hemoadsorption (cases) or sham procedure (controls) and to a 8 drug combination (3 cases and 3 controls for each combination). Hemoadsorption was performed 9 with CytoSorb ${ }^{\circledR}$ (CytoSorbents Corporation, USA). We evaluated 17 drugs (clindamycin, 10 fluconazole, linezolid, meropenem, piperacillin, anidulafungin, ganciclovir, clarithromycin, 11 posaconazole, teicoplanin, tobramycin, ceftriaxone, ciprofloxacin, metronidazole, liposomal 12 amphotericin B, flucloxacillin and cefepime). Repeated blood sampling from the extracorporeal 13 circulation (adsorber inlet/outlet, sham circulation) were performed within six hours of 14 administration. Total clearance and adsorber-specific clearances were computed at each time 15 point.

16 Results: Hemoadsorption was associated with increased clearance of all study drugs, except for 17 ganciclovir. Its impact on total body clearance was major for fluconazole (+282\%), linezolid $18(+115 \%)$ and amphotericin B $(+75 \%)$. It was minor for posaconazole $(+32 \%)$, teicoplanin $19(+31 \%)$, anidulafungin $(+23 \%)$, piperacillin $(+19 \%)$, flucloxacillin $(+16 \%)$, metronidazole $20(+16 \%)$ and ciprofloxacin $(+15 \%)$ and insignificant $(<10 \%)$ for all other drugs. Hemoadsorber 21 clearance declined over time with even delayed desorption for beta-lactams. It was moderately 22 correlated with drug's lipophilicity $\left(\mathrm{p}=0.01 ; \mathrm{r}^{2}=0.43\right)$.

23 Conclusions: Hemoadsorption with CytoSorb ${ }^{\circledR}$ has limited effect on the pharmacokinetics of 24 most tested anti-infective drugs but appears to increase fluconazole, linezolid and liposomal 25 amphotericin B clearance. Studies in humans with sepsis are required to confirm these findings.

26 Keywords: Pharmacokinetics; anti-bacterial agents; antifungal agents; sepsis; drug monitoring, 27 hemoadsorption; CytoSorb 


\section{PHARMACOKINETICS OF ANTI-INFECTIVE AGENTS DURING CYTOSORB HEMOADSORPTION: AN EXPERIMENTAL STUDY}

\section{BACKGROUND}

Sepsis is a major health problem worldwide, affecting close to 50 million individuals each year and leading to 11 million deaths [1]. Its recognition has been identified as a global health priority by the WHO in 2017. Sepsis results from a dysregulated host response to infection [2]. Activation of both complement and coagulation systems lead to the massive release of pro- and antiinflammatory cytokines in the blood, a phenomenon sometimes referred to as "cytokine storm" [3]. This response, through systemic hypotension, microcirculation alterations, endothelial lesions, as well as metabolism modulation, ultimately leads to cellular apoptosis, organ failure and death.

CytoSorb $^{\circledR}$ (CytoSorbents Corporation, NJ, USA), a recent hemoadsorption device, has been marketed and licensed for extracorporeal cytokine removal within the European Union since 2011[4]. CytoSorb ${ }^{\circledR}$ cartridges can easily be inserted in extra-corporeal circulation circuits. They contain biocompatible polystyrene divinylbenzene copolymer beads coated with polyvinylpyrrolidone capable of removing molecules of mid-molecular weight using a combination of hydrophobic or ionic interactions as well as hydrogen bonding $[5,6]$.

The level of evidence supporting the use of CytoSorb ${ }^{\circledR}$ in septic shock remains low and largely observational [7] [8-11]. In their latest statement, experts from the Surviving Sepsis Campaign prompted for further research and did not recommend for or against blood purification techniques[12]. In this context, safety parameters are of particular importance in the decision of initiating such therapy in a patient. So far, post marketing surveillance and data from published literature has not suggested major adverse events besides occasional thrombocytopenia. However, the potential removal of life-saving medications such as antibiotics in sepsis requires particular attention [4]. Indeed, little is known about the effect of CytoSorb ${ }^{\circledR}$ on antibiotics' pharmacokinetics. In vitro models have confirmed its ability to remove some antibiotics from the blood [13]-[14]. However, these one-compartment models have numerous limitations and their results might not be translatable to humans. Authors have reported cases suggesting a minor 
30 influence on serum blood levels [15-17]. However, these reports lack consistency and

31 reproducibility.

32 Accordingly, we have designed an experimental animal study to determine the influence of

33 hemoadsorption with CytoSorb ${ }^{\circledR}$ on the pharmacokinetics of anti-infective agents commonly

34 prescribed in sepsis.

\section{MATERIALS AND MethodS}

\section{$36 \quad$ Ethics and legal aspects}

37 The study was approved by the State Office for Occupational Safety, Consumer Protection and

38 Health - Department of Consumer Protection (Brandenburg, Potsdam, Germany), approval

39 number 2347-3-2018. According to the German animal protection law, no additional approval by

40 an Ethics Committee was necessary. The present report was prepared following the ARRIVE

41 guidelines for animal research[18]. The experimental study was conducted in a medical

42 competence center located in Wendisch Rietz, (Germany), in compliance with German law for

43 animal protection.

\section{$44 \quad$ Animal preparation and monitoring}

45 We included 24 healthy German landrace pigs (10 female, 14 male) with a body weight of 45-

$46 \quad 60 \mathrm{~kg}$ (mean $52.3 \mathrm{~kg}$ ). Pigs were pre-medicated with an initial intramuscular injection of ketamine

$47 \quad(15 \mathrm{mg} / \mathrm{kg})$, midazolam $(0.25 \mathrm{mg} / \mathrm{kg})$ and azaperon $(6 \mathrm{mg} / \mathrm{kg})$. Sedation was maintained using a

48 continuous intravenous infusion of ketamine $(10 \mathrm{mg} / \mathrm{kg} / \mathrm{h})$ and midazolam $(0.5 \mathrm{mg} / \mathrm{kg} / \mathrm{h})$.

49 Pancuronium was administered for muscle relaxation as required. Anticoagulation with heparin

50 was administered. Surgical tracheostomy was performed to allow conventional mechanical

51 ventilation (Evita XL or Oxylog 3000; Draegerwerk AG \& Co KG Luebeck, Germany). Surgical

52 catheterization of the carotid artery and jugular vein was performed (respectively Avanti and

53 Avanti plus sheath introducer; Cordis Miami, FL, USA) to respectively allow for blood pressure

54 monitoring and enable fluid and medication administration. Vital signs were monitored

55 throughout the experiment (Philips M3046A Philips IntelliVue MP5; Philips, Amsterdam, The

56 Netherlands). Finally, a 12 Fr double lumen catheter (dualyse expert; Vygon GmbH \& Co KG,

57 Aachen, Germany) was inserted in either the femoral of jugular vein to enable extracorporeal 
58 circulation. All animals were euthanized at the end of the experiment, while fully sedated, by

59 simultaneous intravenous potassium chloride and pancuronium administration.

60 Experimental design

61 Four experiments were conducted corresponding to four antibiotics combinations (Table 1).

62 During each experiment, six animals were prepared as described above. After the administration

63 of the antibiotic combination, animals were randomly allocated to either hemoadsorption with

64 CytoSorb $^{\circledR}$ (cases) or sham hemoperfusion (control group) on a one to one ratio.

\section{$65 \quad$ Extracorporeal circulation}

66 A schematic representation of the extracorporeal circulation (ECC) is available in the 67 supplementary material. It was established in all animals with a dedicated device [BM11a, Baxter, 68 Deerfield, IL, USA) and corresponding circuit (BM11-Lines-BA-HP (tube system set BM1169 hemoperfusion adult set; VE17; BLD-clamp/VE); Baxter, Deerfield, IL, USA]. For animals 70 allocated to the intervention group (table 1), a CytoSorb ${ }^{\circledR}$ cartridge was inserted in the ECC. For 71 those allocated to the control group no cartridge was integrated (sham hemoperfusion). ECC was 72 started one hour after the start of study antibiotic administration. Blood flow rate was kept 73 between 150 and $200 \mathrm{~mL} / \mathrm{min}$ throughout the experiment.

\section{$74 \quad$ Blood samples and laboratory analysis}

75 Blood samples were collected before the initiation of the antibiotics infusion, then respectively 5, $7630,90,250$ and 330 minutes after adsorber / sham procedure initiation. For animals allocated to 77 the intervention group, we collected two samples per time point: before (inlet) and after (outlet) 78 the absorber. For those allocated in the control group, we collected a single systemic sample (Fig. 79 1). All samples (approx. $9 \mathrm{~mL}$ ) were drawn into EDTA monovettes (Sarstedt AG \& Co KG, 80 Nuembrecht, Germany). They were then centrifuged at 30'000 rpm for $10 \mathrm{~min}$, split into two $812 \mathrm{~mL}$ Eppendorf tubes (Eppendorf AG, Hamburg, Germany) and frozen at $-20^{\circ} \mathrm{C}$. Drugs plasma 82 levels were determined quantitatively by liquid chromatography tandem mass spectrometry (LC83 MS/MS) (MS/MS: API 2000 or API 4000; Sciex, Nieuwerkerk aan den Ijssel, The Netherlands; 84 HPLC pump: Agilent Technologies, Santa Clara, CA, USA; CTC autosampler: Sciex) in a human 85 medical laboratory (Bioscientia $\mathrm{GmbH}$, Ingelheim, Germany). 
Pharmacokinetic parameters calculations

87 Pharmacokinetics parameters were computed individually for each study drug and each animal

88 using standard non-compartmental calculations and considering first order elimination kinetics.

89 All calculations were performed using Microsoft Excel 2016 (Microsoft Corp., Redmond, WA,

90 USA).

91 Area under the plasma drug concentration curves were calculated using the log trapezoidal rule

92 based on the last measurement (AUCo-last) and with extrapolation to infinity assuming a constant

93 elimination rate (AUCo-inf). Total clearance $\left(\mathrm{CL}_{\mathrm{tot}}\right)$ could be deduced from the dose (D):

$\mathrm{CL}_{\text {tot }}=\mathrm{D} / \mathrm{AUCo}-\mathrm{inf}$

95 Total amount eliminated during the study period ( $\mathrm{D}_{\mathrm{TE}}$ ) was calculated using the following 96 formula:

$$
\mathrm{D}_{\mathrm{TE}}=\mathrm{D} \times \text { AUCo-last / AUCo-inf }
$$

98 In addition, for animals allocated to the adsorber arm, absorber's instantaneous removal amount

$99\left(D_{I R}\right)$ were evaluated based on the following formula:

$$
\mathrm{D}_{\mathrm{IR}}=\mathrm{QP}_{\mathrm{P}}([\text { inlet }]-[\text { oulet }])
$$

101 where $Q_{p}$ is the effective plasmatic flow (hematocrit considered to be 40\%), [inlet] the drug 102 concentration in the pre-adsorber sample and [outlet] the drug concentration in the post adsorber 103 sample. Cumulative removal attributable to the adsorber during study period $\left(\mathrm{D}_{\mathrm{CC}}\right)$ was calculated 104 using the log trapezoidal rule on instantaneous absorption rates. Finally, overall adsorber 105 clearance during study period (CLc) could be estimated:

$$
\mathrm{CL}_{\mathrm{C}}=\mathrm{CL}_{\text {tot }} \mathrm{x} \mathrm{D}_{\mathrm{CC}} / \mathrm{D}_{\mathrm{TE}}
$$

107 For each drug, we report mean clearance and standard deviation by study group. Finally, we 108 calculated the relative part of the hemoadsorber on overall animal total clearance (percent):

$$
\mathrm{CL}_{\mathrm{C}} / \mathrm{CL}_{\text {tot }} \mathrm{X} 100
$$

110 We considered the impact of the adsorber on overall clearance to be major if it was associated 111 with a $>50 \%$ increase in total clearance, minor if this increase was between 10 and $50 \%$ and 112 insignificant if it was $<10 \%$. 
114 To evaluate the impact of drugs' physico-chemical properties on adsorber removal, we assessed

115 the correlation between such properties and calculated attributable clearances. For each study 116 drug, we obtained octanol-water partition coefficient (logP), octanol-water distribution 117 coefficient $(\log \mathrm{D})$, acid dissociation constant at logarithmic scale (pKas), molecular electric 118 charge (positive, negative, neutral or zwitterion), protein binding or molecular weight. These data 119 were obtained using Chemaxon ${ }^{\circledR}$ online molecular library.

\section{$120 \quad$ Statistical analyses}

121 Between-groups comparisons were conducted using bilateral student t-test. Correlation analyses 122 were performed using Pearson test. The strength of the correlation was assessed according to the 123 correlation coefficient $(\rho)$ and considered to be strong $(\rho>0.8)$, fair $(0.6<\rho \leq 0.8)$, moderate $124(0.4<\rho \leq 0.6)$ or weak $(\rho \leq 0.4)$. For all analyses a $p$ value $<0.05$ was considered to be statistically 125 significant. All analyses were performed using Graphpad Prism 8.3 (Graphpad Software Inc.).

\section{RESULTS}

127 Measured plasma concentrations and calculated clearances for all study drugs are reported in the 128 supplemental material (Fig. S2-S5).

\section{Overall hemoadsorber clearance}

130 Figure 1 depicts mean overall hemoadsorber clearance measured during the study period for each 131 study drug under our experimental conditions. Except for ganciclovir $(-0.3 \mathrm{~L} / \mathrm{h})$, all values were 132 positive indicating removal of the drug by the procedure. Five drugs (linezolid (4.6, SD 0.4), 133 posaconazole (4.2 SD 0.7), fluconazole (4.0 SD 0.4), clindamycin (3.9 SD 0.2) and 134 clarithromycin (3.3 SD 0.8) had a clearance $>3 \mathrm{~L} / \mathrm{h}$. Clearance was less than $2 \mathrm{~L} / \mathrm{h}$ in all other 135 molecules.

\section{Relative part of hemoadsorber over total body clearance}

137 Figure 2 presents, for each study drug, the impact of the hemoadsorber's associated clearance on 138 total clearance. The hemoadsorber was associated with a major $(>50 \%)$ increase in total clearance 139 for fluconazole $(+282 \%)$, linezolid $(+115 \%)$, liposomal amphotericin B $(+75 \%)$. The observed 140 increase was minor $(10-50 \%)$ for posaconazole $(+32 \%)$, teicoplanin $(+31 \%)$, anidulafungin 
$141(+23 \%)$, piperacillin $(+19 \%)$, flucloxacillin $(+16 \%)$, metronidazole $(+16 \%)$ and ciprofloxacin

$142(+15 \%)$. It was insignificant $(<10 \%)$ for clindamycin $(+7 \%)$, clarithromycin $(+5 \%)$, meropenem

$143(+7 \%)$, ceftriaxone $(+5 \%)$, tobramycin $(+6 \%)$ and cefepime $(+1 \%)$. Total body clearance was 144 decreased for ganciclovir (-3\%).

\section{$145 \quad$ Kinetics of adsorber associated clearance}

146 As depicted in figure 3 and 4, antibiotics clearance by the adsorber was not constant throughout 147 the study period. For beta-lactams (piperacillin, flucloxacillin, ceftriaxone, cefepime and 148 meropenem), it decreased progressively, even reaching negative values at the end of the 149 experiment. For most other drugs (fluconazole, posaconazole, liposomal amphotericine B, 150 linezolid, clarithromycin and teicoplanin), adsorber clearance decreased slowly but remained 151 positive throughout the experiment. The clearance of some molecules became almost null 152 respectively after one (anidulafungin, tobramycin, ganciclovir), two (metronidazole) or six 153 (ciprofloxacin) hours of therapy and remained so for the rest of the experiment.

\section{$154 \quad$ Factors associated with overall hemoadsorber clearance}

155 Overall hemoadsorber clearance appeared to increase proportionally with the octanol-water 156 partition coefficient of drugs $(\log P)$ i.e. their lipophilicity $\left(p=0.01 ; r^{2}=0.43\right)$ and to a lesser degree 157 with the $\log \mathrm{D}$ value $\left(\mathrm{p}=0.01 ; \mathrm{r}^{2}=0.36\right)$. There was no significant association with $\mathrm{pKa}$, molecular 158 electric charge, protein binding or molecular weight.

\section{DISCUSSION:}

\section{$160 \quad$ Key findings}

161 We have conducted an experimental study on 24 pigs to assess the impact of hemoadsorption 162 with CytoSorb ${ }^{\circledR}$ on the pharmacokinetics of a panel of anti-infective drugs commonly utilized in 163 the management of patients with sepsis. We found that for most drugs the procedure was 164 associated with a relatively high clearance. However, when endogenous clearance was 165 considered, we found that the additional clearance provided was major for only a few drugs 166 (fluconazole, linezolid and liposomal amphotericin) but minor $(<50 \%)$ or insignificant $(<10 \%)$ 167 for most other tested drugs. Importantly, we observed that the kinetics of clearance were not stable 168 over time, with highest clearance observed during the first hours of therapy, often followed by a 169 rapid decline and even desorption for some drugs (in particular beta-lactams). Finally, we found 
170 that lipophilicity was the only pharmacokinetic factor moderately associated with overall

171 hemoadsorber clearance.

\section{$172 \quad$ Comparison with previous studies}

173 These first systematic data from in-vivo experiments have to be compared to in-vitro studies.

174 Koenig et al. observed strong adsorption of anti-infectives to the CytoSorb ${ }^{\circledR}$ adsorber with normal

175 saline or human albumin as perfusion fluid. Adsorption was markedly reduced for two anti-

176 infectives, namely meropenem and ciprofloxacin, if reconstituted blood was used for perfusion.

177 However, Koenig et al. integrated the adsorber into a continuous veno-venous hemodialysis, so

178 the results do not resemble pure hemoadsorption alone [14]. In addition, such data does not

179 consider endogenous clearance and therefore the real impact of CytoSorb ${ }^{\circledR}$ on in-vivo

180 pharmacokinetics is difficult to infer.

181 Other available data consist of case reports. The low clindamycin clearance observed in a young 182 patient with refractory septic shock caused by Panton Valentin leucocidin producing methicillin 183 resistant Staphylococcus aureus is consistent with the minimal effect of CytoSorb ${ }^{\circledR}$ on 184 clindamycin overall clearance $(+4.7 \%)$ observed in our study[16]. Similarly, immediate removal 185 of teicoplanin with a saturable process was described by Dimski et al[17]. This is in full agreement 186 with our data which demonstrate a high initial removal followed by progressive decline. Other 187 observations have reported substantially lower linezolid peak levels during CytoSorb ${ }^{\circledR}$ adsorption $188[15,19]$. This is consistent with our finding of a doubled clearance of this molecule during 189 therapy.

190 A high affinity of CytoSorb $^{\circledR}$ for lipophilic molecules particularly in the range up to 191 approximately $55 \mathrm{kDa}$ has also been suspected [14, 20]. We found a weak but significant 192 correlation between the $\log \mathrm{P}$ and hemoadsorber associated clearance. However, this property 193 alone cannot be used to predict the pharmacological impact of the hemoadsorber on drugs' 194 pharmacokinetics. Indeed, when total clearance is considered, CytoSorb ${ }^{{ }^{\prime}} \mathrm{s}$ effect on total 195 clearance was limited for some drugs with high $\log \mathrm{P}$ values (i.e. posaconazole, clarithromycin, 196 flucloxacillin and clindamycin) while it was relatively important for some drugs with low logP 197 values (fluconazole, linezolid or liposomal amphotericine B). This further highlights the need to 198 consider hemoadsorber clearance relative to the overall clearance.

199 Finally, in vitro studies have described that CytoSorb $^{\circledR}$ 's adsorptive capacities were saturable [17] 200 and even to be subject to desorption[21]. Our study confirms these findings for the first time in 
201 vivo. The ability of polyvinylpyrrolidone, the substance covering CytoSorb ${ }^{\circledR}$ s beads, to adsorb

202 and desorb molecules has in principle been described in technical settings other than

203 hemoadsorption, and the substance was even proposed to be used as a component

204 of pharmaceutical drug delivery systems [22].

\section{$205 \quad$ Strengths and limitations}

206 To the best of our knowledge, this is the first in vivo experimental study conducted to evaluate

207 the impact of CytoSorb on the pharmacokinetics of anti-infective drugs. We tested a wide panel

208 of medications commonly used in clinical practice. We have conducted sound analyses with

209 thorough pharmacokinetics models. However, it has several limitations worth discussing.

210 First, our experimental study was conducted in healthy animals and our results might not directly

211 be translatable to humans with septic shock. Indeed, drugs pharmacokinetics might vary from

212 species to species. For instance, the clearances of ceftriaxone and teicoplanin measured in our

213 model were higher than values previously reported in humans (respectively $8.4 \mathrm{vs} 1.0 \mathrm{~L} / \mathrm{h}$ and 5.4

214 vs $0.7-1.0 \mathrm{~L} / \mathrm{h}$ ) while that of linezolid was lower (8.8 vs $3.7 \mathrm{~L} / \mathrm{h})[23,24]$. In addition, and more

215 importantly, pharmacokinetic parameters are known to be massively altered in sepsis (increased 216 dilution volume, decreased protein binding etc) particularly in case of associated acute kidney

217 injury or liver failure. Besides, in patients with sepsis, CytoSorb ${ }^{\circledR 1}$ s adsorptive capacities might

218 be modified, typically by competitive adsorption of other molecules such as pro-inflammatory

219 mediators. The net effect of such competition is unknown and might lead to desorption or

220 decreased drug adsorption. Further studies in humans with sepsis are therefore required to confirm

221 or refute our findings.

222 Second, our protocol, enabled us to compute clearances obtained during the first 6 hours of

223 CytoSorb adsorption, a duration lower than the manufacturer's recommended therapy (24 hours).

224 Hence, a delayed effect of CytoSorb therapy for instance total desorption (i.e. beta-lactams) or more significant binding (i.e. posaconazole) cannot be ruled out. However, our kinetics analyses strongly suggest that the majority of the adsorption process takes place in the first hours of 227 therapy.

228 Third, medications were not administered separately but as a group, and their pharmacokinetics 229 might have influenced each other through binding competition. However, our findings for drugs 230 classes (beta-lactams and azoles) were robust and consistent even if these medications were 231 administered in different group combinations. 
233 Based on our data, some tentative recommendations can be formulated. Obviously, human studies

234 should be performed before these recommendations are implemented in clinical practice.

235 The net influence of hemoadsorption with CytoSorb ${ }^{\circledR}$ on beta-lactams' pharmacokinetics appears 236 to be minimal. In addition, the initial adsorption followed by desorption might even be beneficial 237 in terms of pharmacodynamics. Indeed, the intervention might optimize antimicrobial exposure 238 and the activity of such time dependents agents. Hence, no dose adaptation would theoretically 239 be required for this class of medications.

240 On the other hand, the observed initial removal of tobramycin, a concentration dependent drug, 241 might be associated with a decrease in its antibacterial clinical efficacy. Here, a dose increase, 242 accounting for the additional clearance, would be recommended. A temporary interruption of the 243 adsorption therapy prior to drug administration could represent an alternative. The latter would 244 have the theoretical advantage of enabling a high peak level (efficacy) and rapid removal 245 (decreased toxicity).

246 For other drugs included in this study, biologic activity is related to the area under curve (AUC) 247 divided by the minimum inhibitory concentration. This parameter was significantly decreased by 248 CytoSorb $^{\circledR}$ hemoadsorption for three study drugs: fluconazole, linezolid and liposomal

249 amphotericin B. Hence, decreased biological activity is likely and drug dosage adaptation appears 250 advisable. However, the required dose modification is likely to be minor. Indeed, for a drug to be 251 considered as an inductor, a $>125 \%$ increase in clearance is required while a $>200 \%$ increase is 252 required for it to be considered as a moderate inductor| [25]. For all other drugs, the impact of the 253 therapy on their total clearance was small and no major impact on pharmacodynamics would be 254 expected and no dose adaptation would be required at least in patients with normal renal and liver 255 function.

256 In acute kidney injury, or liver failure, the impact of hemoadsorption on total clearance is likely 257 to increase making drug adaptation necessary. In these situations, therapeutic drug monitoring is 258 strongly advised.

\section{CONCLUSIONS:}


260 Hemoadsorption with CytoSorb ${ }^{\circledR}$ has limited effect on the pharmacokinetics of the majority of 261 tested drugs. However, the clearance of fluconazole, linezolid and liposomal amphotericin B 262 appears to be increased by the procedure. These data need to be confirmed in humans with septic 263 shock. In the meantime, therapeutic drug monitoring remains advisable. 


\section{List of abbreviations}

- HA Hemoadsorption

- ECC Extracorporeal circulation

- $\log \mathrm{P}$ octanol-water partition coefficient

- $\log \mathrm{D}$ octanol-water distribution coefficient

\section{DECLARATIONS}

\section{Ethics approval and consent to participate}

The study was approved by the State Office for Occupational Safety, Consumer Protection and Health - Department of Consumer Protection (Brandenburg, Potsdam, Germany), approval number 2347-3-2018. According to the German animal protection law, no additional approval by an Ethics Committee was necessary.

\section{Consent for publication}

Not applicable

\section{Availability of data and material}

The datasets used and/or analyzed during the current study are available from the corresponding author on reasonable request.

\section{Competing interests}

AS has received speaking honorarium from CytoSorbents Europe JS is Senior Director Medical \& Clinical of CytoSorbents Europe DKM has received speaking honorarium from CytoSorbents Europe All other authors stated that they have no conflict of interest.

\section{Funding}

The study was funded by CytoSorbents Europe, Berlin, Germany. The company was involved with the study design. However, data interpretation was conducted independently by AS, PA, TB 
and DKM. The company was allowed to read the draft of the manuscript before submission but had no influence on its content or decision for submission.

\section{Authors' contributions}

AGS: Participated in study design, data interpretation and analyses and drafted the manuscript PA: Performed pharmacokinetic analyses, participated in data interpretation and critically reviewed the manuscript

JS: Participated in study design and critically reviewed the manuscript

MS: Performed the animal experiment and critically reviewed the manuscript

HZ: Planned and monitored the animal experiment and critically reviewed the manuscript

TB: Participated in pharmacokinetic analyses and critically reviewed the manuscript

DKM: Participated in study design, data interpretation and critically reviewed the manuscript

All authors read and approved the final manuscript and agree to be personally accountable for their contribution.

\section{Acknowledgements}

The authors thank Dr Michael Zoller (Munich, Germany) for advising on the interpretation of the results. They also want to thank Dr Sven Giersdorf from CytoSorbents Europe for the support. 


\section{FIGURES AND TABLES TITLES AND LEGENDS}

Figure 1: Total Adsorber Clearance: Clearance attributable to CytoSorb (mean and SD). Values were calculated based on pre and post adsorber measurements at different timepoints. AmphoB lipo: liposomal amphotericin B.

Figure 2: Additional clearance provided by adsorber: The white areas of the bars represent the endogenous drug clearance (without adsorber) while the grey areas represent the additional clearance provided by the adsorber under the experimental conditions. Percentage refer to the relative increase in clearance associated with adsorber insertion. AmphoB lipo: liposomal amphotericin B.

Figure 3: Kinetics of adsorber clearance of beta-lactams (panel a) and antifungals (panel b): Bars represent instantaneous clearance at the different study time points: 30 min $(0.5 \mathrm{~h}), 1$, 2 and 3 hours after therapy initiation as well as the last measure obtained (6 hours). Dotted lines represent total clearance (also represented in figure 2). Reported values are mean and standard deviation. AmphoB lipo: liposomal amphotericin B.

Figure 4: Kinetics of adsorber clearance of other anti-infective agents: Bars represent instantaneous clearance at the different study time points: $30 \mathrm{~min}(0.5 \mathrm{~h}), 1,2$ and 3 hours after therapy initiation as well as the last measure obtained (6 hours). Dotted lines represent total clearance (also represented in figure 2). Reported values are mean and standard deviation.

Table 1: Experimental groups: pigs received different combinations of drugs, followed by initiation of an extra-corporeal circulation with (cases) or without (sham, control) a CytoSorb cartridge. Three animals were randomly allocated to each group. All drugs were administered intravenously one hour before extra-corporeal circulation initiation. 


\section{Supplemental Material}

Figure S1: Extra-corporeal circuit: According to study protocol, 1hr following antibiotic administration, study animals were randomly allocated to either CytoSorb hemoadsorption or sham procedure on a 1:1 basis. For animals allocated to sham procedure, a similar circuit without hemoadsorber was used.

Figure S2: Plasma concentrations (panel A) and calculated clearances (panel B) for betalactams. Full symbols correspond to cases (CytoSorb Hemoadsorption) and open symbols to controls

Figure S3: Plasma concentrations (panel A) and calculated clearances (panel B) for antifungals. Full symbols correspond to cases (CytoSorb Hemoadsorption) and open symbols to controls

Figure S4: Plasma concentrations (panel A) and calculated clearances (panel B) for other drugs (part 1). Full symbols correspond to cases (CytoSorb Hemoadsorption) and open symbols to controls

Figure S5: Plasma concentrations (panel A) and calculated clearances (panel B) for other drugs (part 2). Full symbols correspond to cases (CytoSorb Hemoadsorption) and open symbols to controls 


\section{REFERENCES}

1. Rudd KE, Johnson SC, Agesa KM, Shackelford KA, Tsoi D, Kievlan DR, Colombara DV, Ikuta KS, Kissoon N, Finfer S et al: Global, regional, and national sepsis incidence and mortality, 1990-2017: analysis for the Global Burden of Disease Study. Lancet 2020, 395(10219):200-211.

2. Singer M, Deutschman CS, Seymour CW, Shankar-Hari M, Annane D, Bauer M, Bellomo R, Bernard GR, Chiche JD, Coopersmith CM et al: The Third International Consensus Definitions for Sepsis and Septic Shock (Sepsis-3). JAMA 2016, 315(8):801-810.

3. Tisoncik JR, Korth MJ, Simmons CP, Farrar J, Martin TR, Katze MG: Into the eye of the cytokine storm. Microbiol Mol Biol Rev 2012, 76(1):16-32.

4. Poli EC, Rimmele T, Schneider AG: Hemoadsorption with CytoSorb((R)). Intensive Care Med 2018.

5. Rimmelé T, Kellum JA: Clinical review: Blood purification for sepsis. Critical Care 2011, 15(1):205-205.

6. Malard B, Lambert C, Kellum JA: In vitro comparison of the adsorption of inflammatory mediators by blood purification devices. Intensive Care Medicine Experimental 2018, 6(1):12.

7. Schädler D, Pausch C, Heise D, Meier-Hellmann A, Brederlau J, Weiler N, Marx G, Putensen C, Spies C, Jörres A et al: The effect of a novel extracorporeal cytokine hemoadsorption device on IL-6 elimination in septic patients: A randomized controlled trial. PLoS One 2017, 12(10): 0187015.

8. Friesecke S, Träger K, Schittek GA, Molnar Z, Bach F, Kogelmann K, Bogdanski R, Weyland $\mathrm{A}$, Nierhaus $\mathrm{A}$, Nestler $\mathrm{F}$ et al: International registry on the use of the CytoSorb ${ }^{\circledR}$ adsorber in ICU patients. Medizinische Klinik - Intensivmedizin und Notfallmedizin 2017.

9. Friesecke S, Stecher S-S, Gross S, Felix SB, Nierhaus A: Extracorporeal cytokine elimination as rescue therapy in refractory septic shock: a prospective single-center study. J Artificial Organs 2017, 20(3):252-259.

10. Kogelmann K, Jarczak D, Scheller M, Drüner M: Hemoadsorption by CytoSorb in septic patients: a case series. Critical Care 2017, 21(1):74.

11. Brouwer WP, Duran S, Kuijper M, Ince C: Hemoadsorption with CytoSorb shows a decreased observed versus expected 28-day all-cause mortality in ICU patients with septic shock: a propensity-score-weighted retrospective study. Crit Care 2019, 23(1):317.

12. Rhodes A, Evans LE, Alhazzani W, Levy MM, Antonelli M, Ferrer R, Kumar A, Sevransky JE, Sprung CL, Nunnally ME et al: Surviving Sepsis Campaign: International Guidelines for Management of Sepsis and Septic Shock: 2016. Crit Care Med 2017, 45(3):486-552.

13. Reiter K, Bordoni V, Dall'Olio G, Ricatti MG, Soli M, Ruperti S, Soffiati G, Galloni E, D'Intini $\mathrm{V}$, Bellomo $\mathrm{R}$ et al: In vitro removal of therapeutic drugs with a novel adsorbent system. Blood Purif 2002, 20(4):380-388.

14. Konig C, Rohr AC, Frey OR, Brinkmann A, Roberts JA, Wichmann D, Braune S, Kluge $\mathrm{S}$, Nierhaus A: In vitro removal of anti-infective agents by a novel cytokine adsorbent system. Int J Artif Organs 2019, 42(2):57-64. 
15. Zoller M, Dobbeler G, Maier B, Vogeser M, Frey L, Zander J: Can cytokine adsorber treatment affect antibiotic concentrations? A case report. J Antimicrob Chemother 2015, 70(7):2169-2171.

16. Poli EC, Simoni C, Andre P, Buclin T, Longchamp D, Perez MH, Ferry T, Schneider AG: Clindamycin clearance during Cytosorb((R)) hemoadsorption: A case report and pharmacokinetic study. Int J Artif Organs 2019, 42(5):258-262.

17. Dimski T, Brandenburger T, MacKenzie C, Kindgen-Milles D: Elimination of glycopeptide antibiotics by cytokine hemoadsorption in patients with septic shock: A study of three cases. Int J Artif Organs 2020, 43(12):753-757.

18. Kilkenny C, Browne W, Cuthill IC, Emerson M, Altman DG, National Centre for the Replacement $\mathrm{R}$, Reduction of Amimals in $\mathrm{R}$ : Animal research: reporting in vivo experiments--the ARRIVE guidelines. Journal of cerebral blood flow and metabolism : official journal of the International Society of Cerebral Blood Flow and Metabolism 2011, 31(4):991-993.

19. Morris C, Gray L, Giovannelli M: Early report: The use of Cytosorb haemabsorption column as an adjunct in managing severe sepsis: initial experiences, review and recommendations. J Intensive Care Soc 2015, 16(3):257-264.

20. De Schryver N, Hantson P, Haufroid V, Dechamps M: Cardiogenic Shock in a Hemodialyzed Patient on Flecainide: Treatment with Intravenous Fat Emulsion, Extracorporeal Cardiac Life Support, and CytoSorb(R) Hemoadsorption. Case Rep Cardiol 2019, 2019:1905871.

21. Lang CN, Sommer MJ, Neukamm MA, Staudacher DL, Supady A, Bode C, Duerschmied D, Lother A: Use of the CytoSorb adsorption device in MDMA intoxication: a firstin-man application and in vitro study. Intensive Care Med Exp 2020, 8(1):21.

22. Franco P, De Marco I: The Use of Poly(N-vinyl pyrrolidone) in the Delivery of Drugs: A Review. Polymers (Basel) 2020, 12(5).

23. Goodman L, Brunton L, Chabner B, SKnollmann C: Goodman \& Gilman's Pharmacological Basis of Therapeutics. New York: McGraw-Hill 2011.

24. Targocid_information: https://www.swissmedicinfo.ch/Accept.aspx?Lang=EN. Swissmedicinfo 2017.

25. European_Medicine_Agency: https://www.ema.europa.eu/en/dlocuments/scientificguideline/guideline-investigation-dlrug-interactions-revision-1_en.pdff. 2012. 
Figures

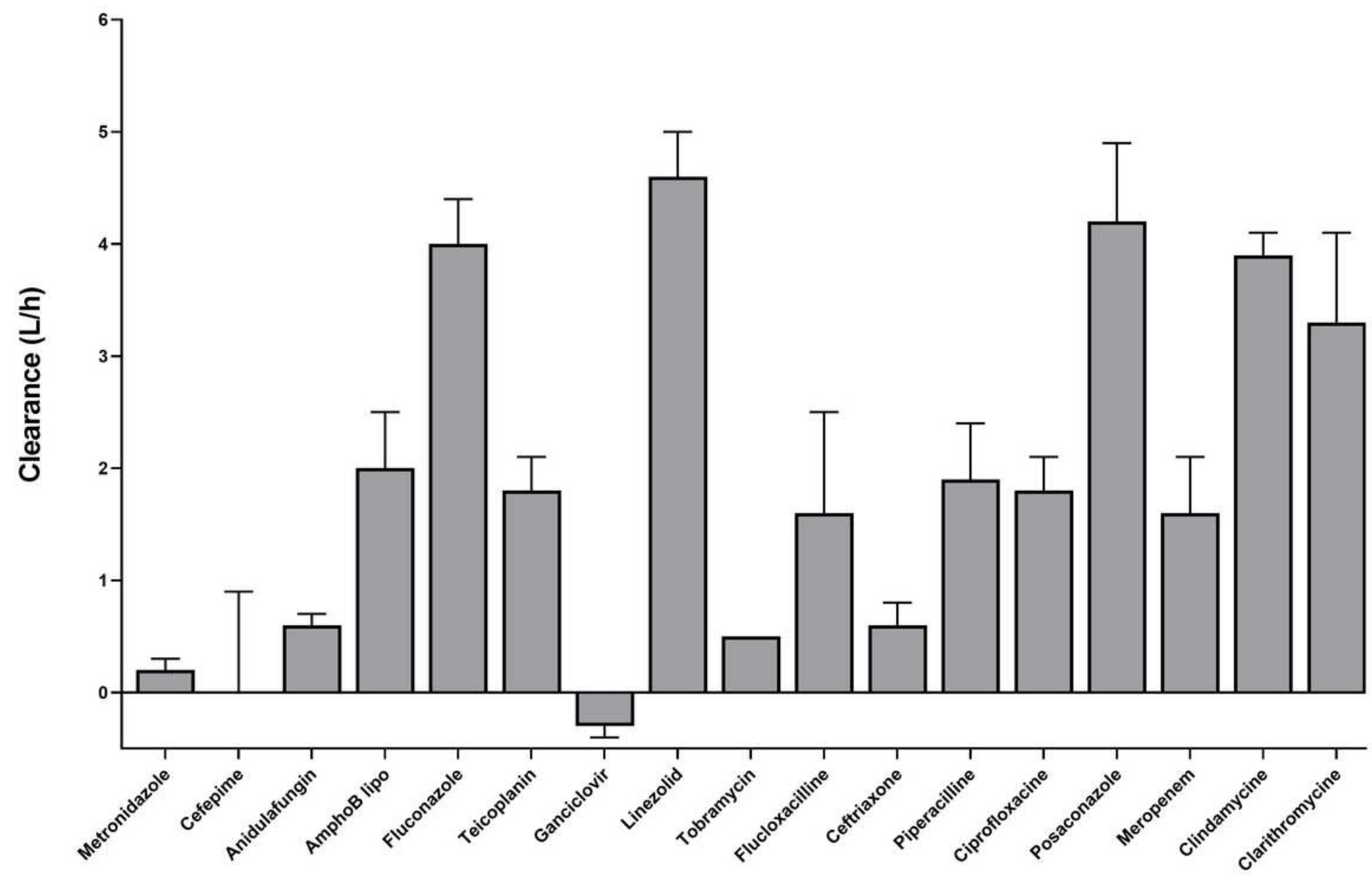

Figure 1

Total Adsorber Clearance: Clearance attributable to CytoSorb (mean and SD). Values were calculated based on pre and post adsorber measurements at different timepoints. AmphoB lipo: liposomal amphotericin B. 


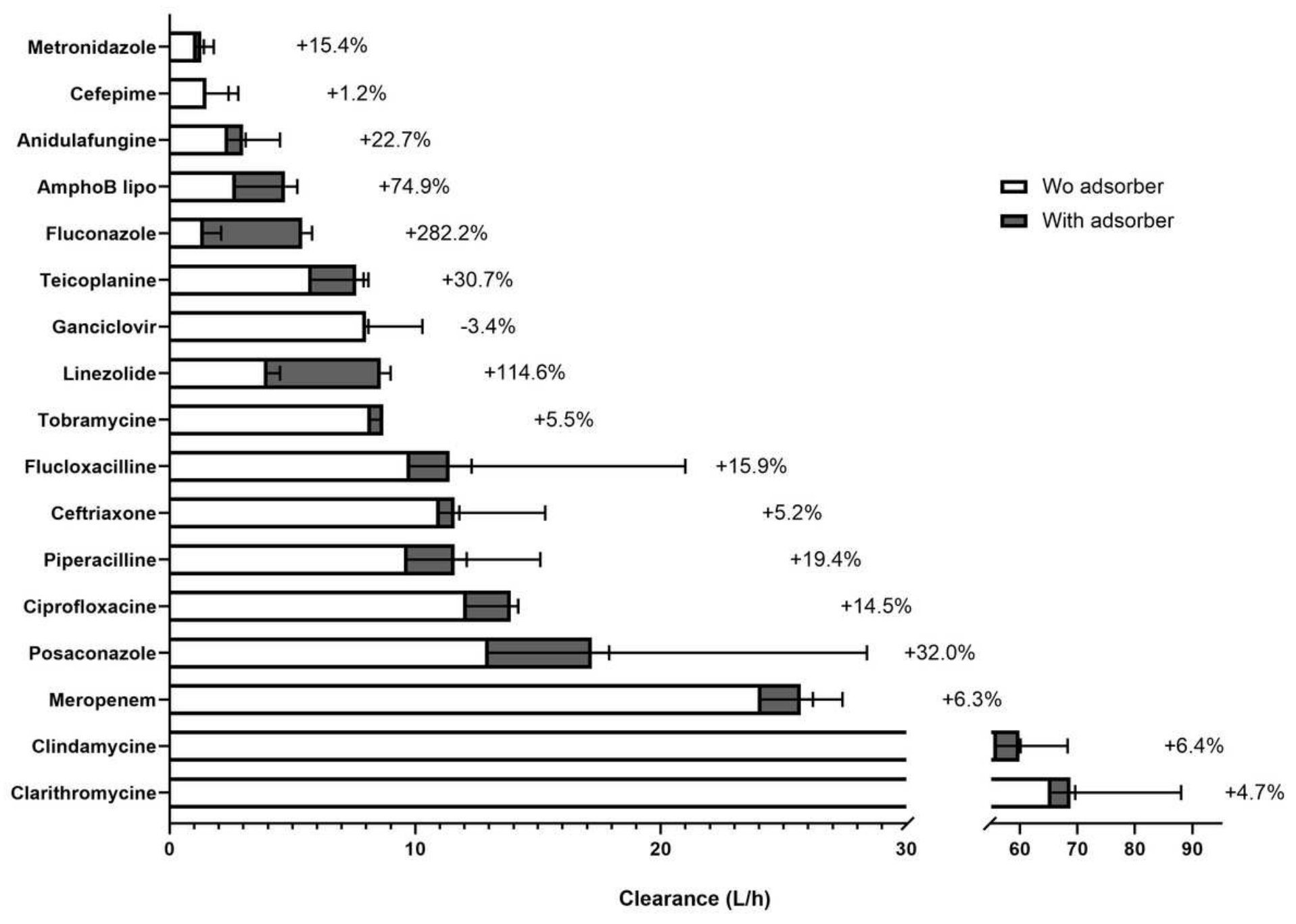

\section{Figure 2}

Additional clearance provided by adsorber: The white areas of the bars represent the endogenous drug clearance (without adsorber) while the grey areas represent the additional clearance provided by the adsorber under the experimental conditions. Percentage refer to the relative increase in clearance associated with adsorber insertion. AmphoB lipo: liposomal amphotericin B. 

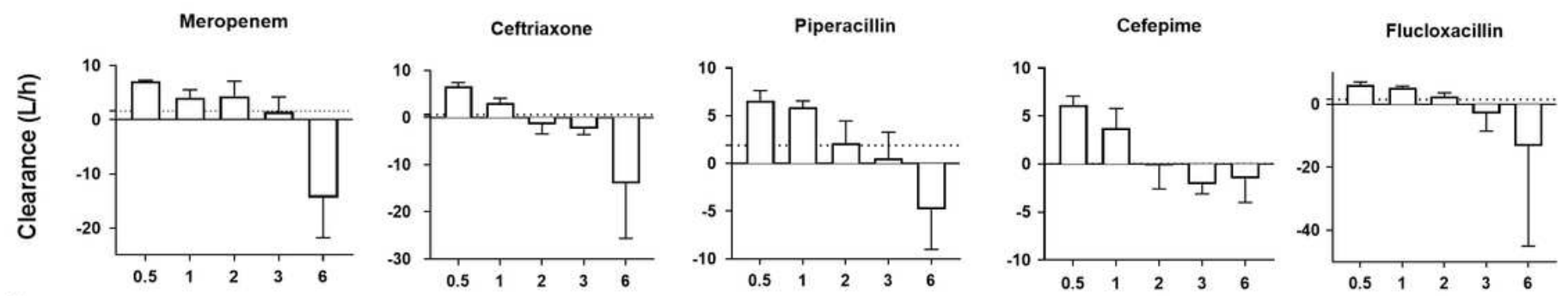

a.
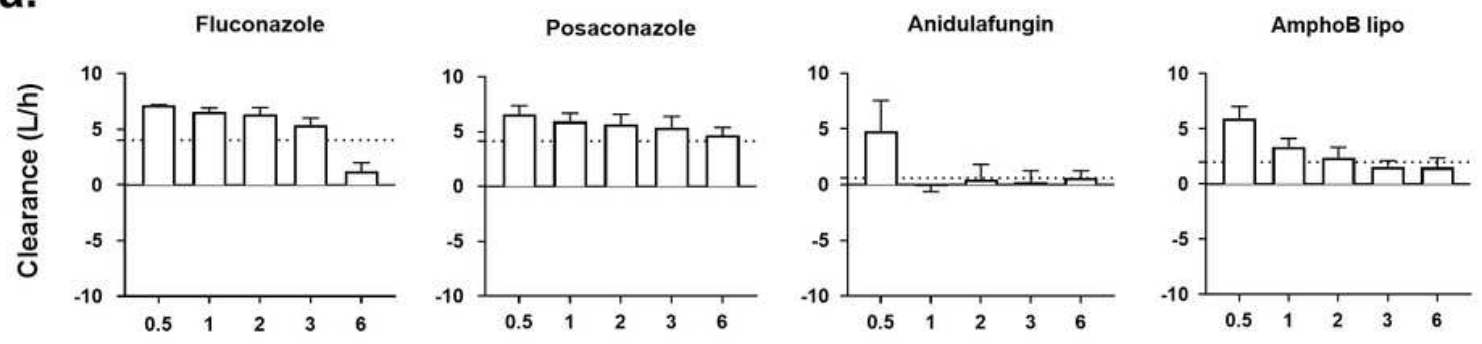

b.

\section{Figure 3}

Kinetics of adsorber clearance of beta-lactams (panel a) and antifungals (panel b): Bars represent instantaneous clearance at the different study time points: $30 \mathrm{~min}(0.5 \mathrm{~h}), 1,2$ and 3 hours after therapy initiation as well as the last measure obtained (6 hours). Dotted lines represent total clearance (also represented in figure 2). Reported values are mean and standard deviation. AmphoB lipo: liposomal amphotericin B.
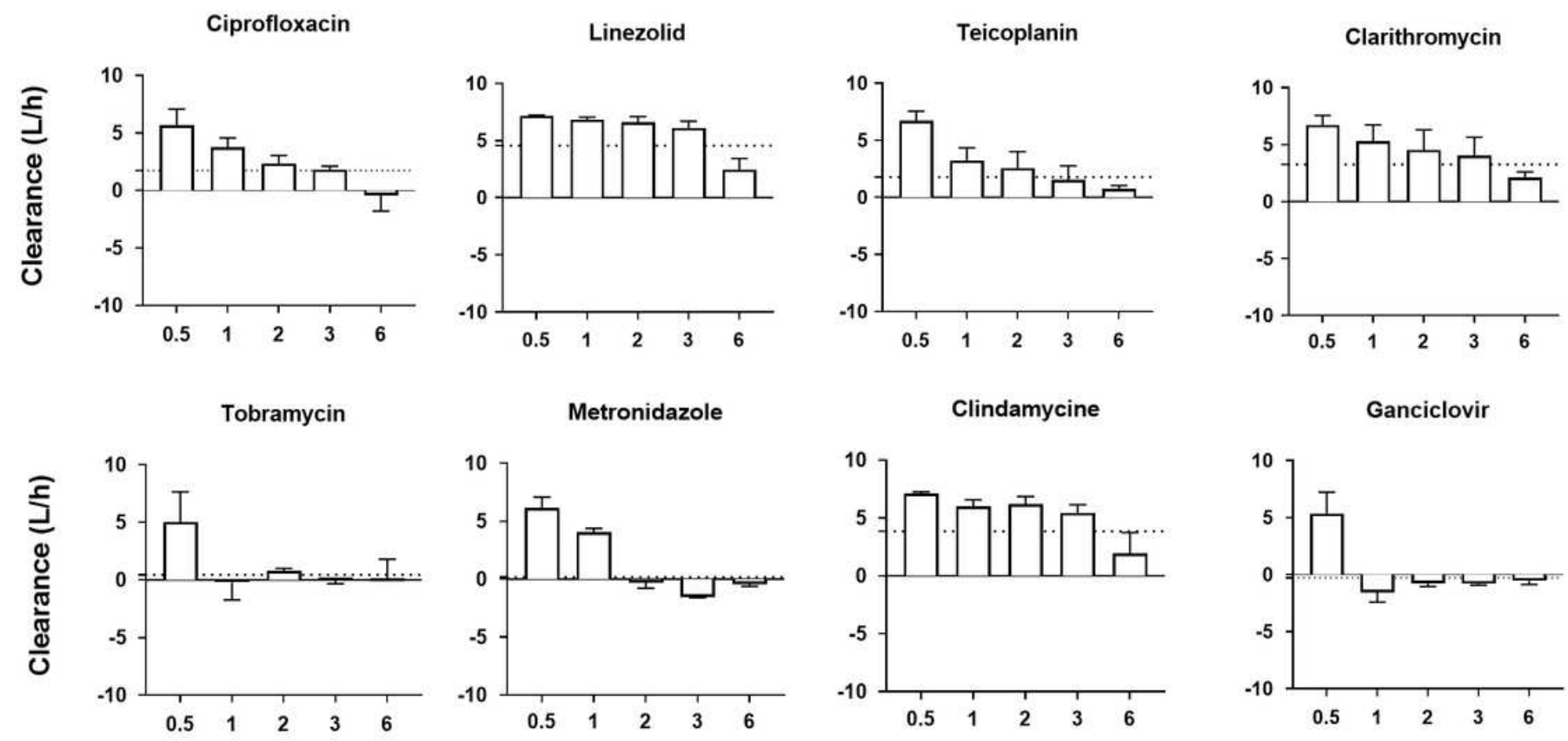

Figure 4 
Kinetics of adsorber clearance of other anti-infective agents: Bars represent instantaneous clearance at the different study time points: 30 min (0.5h), 1, 2 and 3 hours after therapy initiation as well as the last measure obtained (6 hours). Dotted lines represent total clearance (also represented in figure 2). Reported values are mean and standard deviation.

\section{Supplementary Files}

This is a list of supplementary files associated with this preprint. Click to download.

- SupplementalMaterial.docx 